
\title{
R Reseracth Sulure \\ The bacteriostatic effect and mechanism of berberine on Methicillin resistant Staphylococcus aureus in vitro
}

Lei Wang ( $\nabla$ wolei6610@126.com )

Shanghai Eighth People's Hospital

Fangfang Zhou

Shanghai Eighth People's Hospital

Minyi Xu

Shanghai Elghth People's Hospital

Wei Gong

Shanghai Eighth People's Hospital

Shuiying Ji

Shanghai Eighth People's Hospital

\section{Research article}

Keywords: Berberine; Methicillin resistant Staphylococcus aureus (MRSA); Combination; Antibiotics;

Bacteriostatic effect

Posted Date: May 20th, 2019

DOl: https://doi.org/10.21203/rs.2.9640/v1

License: (9) (i) This work is licensed under a Creative Commons Attribution 4.0 International License. Read

Full License 


\section{Abstract}

Background: To observe the bacteriostatic effect of berberine on MRSA, while also exploring the bacteriostatic mechanism of BBR on MRSA. Methods: The MIC of BBR, gentamicin, levofloxacin『amikacin was determined by broth microdilution, while the MICs of BBR combined with gentamicin, levofloxacin『amikacin against MRSA were determined using microdilution checkerboard. Time-killing test were used to determine the kinetics of BBR combined with antibiotics for MRSA. We used conductivity to assess the changes in membrane permeability in response to BBR on MRSA, while also investigating the changes in MRSA morphology by TEM. RNA-sequencing was used to analyze the expression of differentially expressed genes in USA300 after its treatment with BBR. Results: The MICs range of BBR on MRSA was $32-256 \mu \mathrm{g} / \mathrm{mL}$. The range of FICls of BBR combined with gentamicin, levofloxacin囚amikacin were 0.53-1.06, 0.62-1.5, 0.16-1.25. After co-culturing MRSA with BBR at $512 \mathrm{ug} / \mathrm{mL}, 64 \mathrm{ug} / \mathrm{mL}, 8 \mathrm{ug} / \mathrm{mL}$, respectively, the conductivity of these group increased by $8.14 \%, 13.08 \%$ and $12.01 \%$, respectively. Using TEM, we found that low-concentration of BBR had no significant effect on MRSA structure, medium-concentration of BBR thinned the cell wall of MRSA, while highconcentration of BBR destroyed cell wall, leading to bacterial lysis. RNA-sequencing results showed that there were 754 differentially expressed genes in the high-concentration group compared with the control group, of which 561 genes were up-regulated and 193 genes were down-regulated. Compared with the low-concentration group, there were 590 differentially expressed genes, of which 402 genes were up-regulated and 188 genes were down-regulated. Compared with the control group, 19 genes were differentially expressed in the lowconcentration group, of which 11 genes were up-regulated, 8 genes were down-regulated. Conclusions: BBR displayed an excellent bacteriostatic effect on MRSA. BBR combined with antibiotics significantly enhanced the bacteriostatic effect on MRSA. BBR inhibited bacteria by destroying the structure of cell wall. RNAsequencing results demonstrated that the expression of cell wall hydrolysis genes and virulence factor were significantly differentially expressed on MRSA.

\section{Background}

Staphylococcus aureus (S. aureus) is one of the most common pathogenic bacteria in pyogenic infections, causing systemic infections such as local pyogenic infections, pneumonia, pseudomembranous enteritis, pericarditis and sepsis[1]. In recent years, with the widespread use of antibiotics, Methicillin-resistant Staphylococcus aureus (MRSA) has become common drug-resistant bacteria[2]. MRSA is resistant to all the beta-lactams and cephalosporins with the same structure as methicillin, but only sensitive to vancomycin[3]. Vancomycin is the most effective antibiotic against Gram-positive bacteria[4]. However, Vancomycinintermediate Staphylococcus aureus (VISA) appeared in the 1990s, and Vancomycin-resistant Staphylococcus aureus (VRSA) was first found in the United States in 2002[5]. The appearance of VISA and VRSA has drawn more attention on the problem of antibiotic resistance.

Traditional Chinese medicine has been used for thousands of years, and has been consistently effective and feasible in treating and preventing diseases. Berberine (BBR) is the main component of the traditional Chinese medicine Coptis chinensis and Cortex Phellodendri, with an isoquinoline alkaloid structure. BBR is one of the commonly used drugs in the treatment of intestinal infections in China, with moderate price and definite effect[6]. In addition to its broad spectrum bacteriostatic effects[7-9], BBR also has potent anti-inflammatory, anti-oxidant, anti-tumor, hypoglycemic and anti-cardiac arrhythmia qualities[10-14]. Studies also reported that 
BBR had good bacteriostatic effect on E. coli and Bacillus subtilis[15]. Subsequent studies reported that the MIC of BBR against the MRSA standard strain ATCC33591 was $128 \mu \mathrm{g} / \mathrm{mL}$. BBR can affect the aggregation of amyloid fibers in PSMs of MRSA biofilm, thus inhibiting the formation of MRSA biofilm and increasing the bactericidal activity of antibiotics[9]. Current studies have reported that BBR had bacteriostatic effects on MRSA, yet no specific study on its bacteriostatic mechanism has been reported. In our hospital, aminoglycoside antibiotics (GEN, AMI) and quinolone antibiotics (LEV) are routinely used to treat MRSA infection. With the increase of drug resistance, this study seeked to investigate the bacteriostatic effect of BBR and BBR combined with GEN, LEV and AMI on clinical strains of MRSA, while further exploring the bacteriostatic mechanism of BBR on MRSA.

\section{Methods}

\section{Source of strains}

S. aureus standard strain USA300 was a gift from Prof. Lan of Shanghai Institute of Materia Medica, Chinese Academy of Sciences. All 26 strains of MRSA were isolated from inpatient specimens of Shanghai Eighth People's hospital from October 2016 to March 2017. All strains were identified using the VITEK 2 compact microbiology analysis system (BioMérieux Industry, France). In addition, 26 mecA genotypes of MRSA were identified by PCR. The 26 isolated strains of MRSA were numbered as MRSA01 MRSA26.

\section{BBR and antibiotics}

BBR was purchased from Tianzheng Pharmaceutical Co., LTD (Northeast pharmaceutical group, batch number: 0361611030) and was prepared with dimethyl sulfoxide (DMSO) to $32 \mathrm{mg} / \mathrm{mL}$ solution. After filtration and sterilization with 0.22 um filter membrane, BBR solution was separated into sterilized EP tubes and stored at $4^{\circ} \mathrm{C}$ for reserve. GEN (Xinchen Pharmaceutical Co., LTD, batch number: 1607252211), AMI (Shanghai Xinyijinzhu Pharmaceutical Co., LTD, batch number: 1611107), and LEV (Yangtze River Pharmaceutical Co., LTD, batch number: 16080231) were all purchased from the pharmacy of Shanghai Eighth People's hospital. These antibiotics were freshly prepared with sterile water to a concentration of 1024 $\mu \mathrm{g} / \mathrm{mL}$.

\section{Susceptibility testing of the BBR and antimicrobial agents}

According to the 2018 standard of the Clinical and Laboratory Standards Institute (CLSI)[16], the MIC of GEN, LEV, AMI and BBR on MRSA was determined by broth microdilution. GEN, LEV, AMI, and BBR solutions were serially diluted to a final concentration of $8,16,32,64,128,256,512$ and $1024 \mu \mathrm{g} / \mathrm{mL}$ with $\mathrm{M}-\mathrm{H}$ broth. Different concentration of antibiotics or BBR solution was added to a 96-well plate. The bacterial suspension was prepared with $0.5 \mathrm{Mcfarland}$ standard, then diluted to 1:1000 with $\mathrm{M}-\mathrm{H}$ broth. A $50 \mu \mathrm{L}$ bacterial suspension was added to each well of the 96-well plate and incubated in a Heal Force $\mathrm{CO}_{2}$ incubator (Likang, Shanghai, China) at $37^{\circ} \mathrm{C}$ for $24 \mathrm{~h}$. The minimum drug concentration without bacterial growth was MIC. 


\section{Synergy Testing}

5 strains (MRSA01 MRSA05) of MRSA resistant to GEN, 17 strains (MRSA01 MRSA04, MRSA06 MRSA18) resistant to LEV and 6 strains (MRSA02, MRSA04, MRSA07 MRSA10) resistant to AMI were selected for the combined bacteriostatic test. BBR solution was diluted to 4 dilutions $(32,64,128$, and $256 \mu \mathrm{g} / \mathrm{ml})$ with M-H broth. GEN, LEV and AMI were diluted with M-H broth to 8 increasing concentrations $(8,16,32,64,128,256$, 512 , and $1024 \mu \mathrm{g} / \mathrm{ml})$. Bacterial suspensions were prepared with $0.5 \mathrm{Mcfarland}$ standard, then diluted to 1:1000 with $\mathrm{M}-\mathrm{H}$ broth. $50 \mu \mathrm{l}$ of BBR solution $(32,64,128$, and $256 \mu \mathrm{g} / \mathrm{ml})$ and $\mathrm{GEN}$, LEV, AMI solution $(8,16$, $32,64,128,256,512$, and $1024 \mu \mathrm{g} / \mathrm{ml}$ ) were arranged in a 96-well plate, and $100 \mu \mathrm{l}$ bacterial suspension was added to the sterile microporous plate. The final concentrations of BBR were $8,16,32$, and $64 \mu \mathrm{g} / \mathrm{mL}$, respectively. The final concentrations of GEN, LEV and AMI were $2,4,8,16,32,64,128$, and $256 \mu \mathrm{g} / \mathrm{mL}$, respectively. All plates were incubated at $37^{\circ} \mathrm{C}$ for $24 \mathrm{~h}$. After $24 \mathrm{~h}$ incubation, the minimum drug concentration without bacterial growth was considered to be the MIC. The interaction was judged by calculating the fractional inhibitory concentration (FICls). These were calculated as follows:

$\mathrm{FICl} \leq 0.5,0.5<\mathrm{FICl} \leq 1,1<\mathrm{FICl} \leq 2,2 \leq \mathrm{FICl}$ represents synergy, additivity, indifference, and antagonism, respectively[17].

\section{Concentration-killing curve}

MRSA02 strain, which was resistant to all 3 antibiotics, was selected for the concentration-killing curve test. BBR and antibiotic solutions were diluted to final concentrations $(16,32,64,128,256,512$, and $1024 \mu \mathrm{g} / \mathrm{mL})$ with $\mathrm{M}-\mathrm{H}$ broth. $50 \mu \mathrm{L}$ BBR or antibiotic solutions were added to each well of a 96 -well plate. Bacterial suspensions were prepared with $0.5 \mathrm{Mcfarland}$ standard, then diluted to 1:1000 with $\mathrm{M}-\mathrm{H}$ broth. $50 \mu \mathrm{L}$ bacterial suspensions were added to the 96 -well plate. The initial OD value of each well was measured by an enzyme-linked immunometric meter (Biotek) for 3 times and the average value was set as the base value. After incubating at $37^{\circ} \mathrm{C}$ for $24 \mathrm{~h}$, the OD value was measured again for 3 times and the average value was calculated. The growth of bacteria was determined by the difference of OD values measured before and after $24 \mathrm{~h}$ of incubation.

\section{Time-killing curves analysis}

MRSA02 strain, which was resistant to all 3 antibiotics, was selected for the time-killing curve test. BBR solution was diluted to 4 concentrations $(32,64,128$, and $256 \mu \mathrm{g} / \mathrm{mL})$ with $\mathrm{M}-\mathrm{H}$ broth. GEN, LEV, and AMI were diluted with $\mathrm{M}-\mathrm{H}$ broth to 8 concentrations $(8,16,32,64,128,256,512$, and $1024 \mu \mathrm{g} / \mathrm{mL})$. Bacterial suspensions were prepared as before. $50 \mu$ l of BBR solution $(32,64,128$ and $256 \mu \mathrm{g} / \mathrm{mL})$ and GEN, LEV, AMI solution $(8,16,32,64,128,256,512$ and $1024 \mu \mathrm{g} / \mathrm{mL})$ were arranged in a 96-well plate. $100 \mu \mathrm{L}$ bacterial suspensions were added to the sterile microporous plate. The final concentrations of BBR were $8,16,32$, and $64 \mu \mathrm{g} / \mathrm{mL}$, respectively, while the final concentrations of GEN, LEV, and AMI were $2,4,8,16,32,64,128$, and $256 \mu \mathrm{g} / \mathrm{mL}$, respectively. The initial OD value of each well was measured by an enzyme-linked immunometric meter (Biotek) at $0 \mathrm{~h}$ for 3 times, and the average value was set as the base value. The plate was then 
incubated at $37^{\circ} \mathrm{C}$, and the $\mathrm{OD}$ values were measured (repeated 3 times) at 4, 8, 12, 16, 20 and $24 \mathrm{~h}$ time points, respectively. The average OD value of each time point was calculated. The growth of bacteria was determined by the difference of OD values.

\section{Conductivity test}

MRSA02 strain was selected for the conductivity test. Measuring the conductivity of culture medium with a conductivity meter is to measure the ionic concentration of culture medium. The higher the ion concentration is, the greater the conductivity. BBR solution at 16,128 , and $1024 \mu \mathrm{g} / \mathrm{mL}$ were added to the bacterial suspension culture at logarithmic phase. The final concentrations of BBR solution were 8,64 , and $512 \mu \mathrm{g} / \mathrm{mL}$, respectively. $5 \mathrm{~mL}$ of suspension was taken and centrifuged at $2800 \times \mathrm{g}$ for $10 \mathrm{~min}$ at $0,0.5,1,1.5,2,2.5,3,3.5$ and $4 \mathrm{~h}$, respectively. Conductivity of the supernatant was measured by DDS-11A conductivity meter (Leici, Shanghai) after a 20 -time dilution of the supernatant. Absolute ethanol was taken as the control group. The test was repeated 3 times, and the average value was obtained.

\section{TEM examination}

MRSA02 strain was selected for the TEM examination.Bacterial suspensions were prepared with 0.5 Mcfarland standard. After culture with 8,64 , and $512 \mu \mathrm{g} / \mathrm{mL}$ BBR solution at $37^{\circ} \mathrm{C}$ for $24 \mathrm{~h}, 10 \mathrm{~mL}$ solution was taken and centrifuged at $12000 \times \mathrm{g}$ for $10 \mathrm{~min}$, and the supernatant was removed to collect $0.5 \mathrm{~mL}$ sediment. After fixation with $2 \%$ glutaraldehyde PBS fixing solution at $4^{\circ} \mathrm{C}$ for $2 \mathrm{~h}$, the sediment was washed twice with PBS. After fixed with $1 \%$ osmium acid-PBS fixing solution at $4^{\circ} \mathrm{C}$ for $2 \mathrm{~h}$, cells were washed twice with PBS. Bacteria were dehydrated step by step with ethanol, replaced with propylene oxide and immersed in epoxy resin. They were then sliced with a LKB V ultrathin section machine and stained with lead citrate. The changes in MRSA cell wall were observed by an $\mathrm{H}-7650$ transmission electron microscope (HITACH, Japan).

\section{RNA isolation, mRNA enrichment and sequencing}

After culturing S. aureus USA300 strain to logarithmic phase, USA300 was cultured with BBR of different concentration for $3 \mathrm{~h}$, and total RNA was extracted. The samples were divided into 3 groups: normal control group (group A), high concentration group (group B, 1/2 MIC, $64 \mathrm{ug} / \mathrm{mL}$ ), and low concentration group (group C, 1/8 MIC, $16 \mathrm{ug} / \mathrm{mL}$ ). Each group had 3 repetitive samples. Total RNA was extracted from bacterial cells using RNeasy Mini kit (Qiagen)[18]. Qubit 2.0 RNA detection kit was used to quantify total RNA accurately to determine the amount of total RNA added to the library. rRNA was removed by kit and fragmentation buffer was added to the obtained mRNA to make the fragments short. The fragmented RNA was used as template to synthesize the first strand of the DNA with random hexamers, and the second strand was synthesized by adding buffer, dNTPs, RNase H and DNA polymerase I. The product was purified by QiaQuick PCR kit and eluted by EB buffer. After terminal repair, base $A$ and sequencing connector were added, the target fragments were collected by agarose gel electrophoresis, and amplified by PCR. The whole library was prepared and the library was sequenced by Illumina HiSeq2500[19]. 


\section{Results}

\section{Distribution and drug resistance status of 26 clinical isolated MRSA strains}

A standard strain USA300 was selected as control. The 26 clinical isolates of MRSA mainly came from respiratory medicine department (8/26), geriatrics $(7 / 26)$ and ICU (3/26) (Table 1$)$. Respiratory tract and wound specimens accounted for $57.69 \%$ and $26.92 \%$ of sources 26 clinical MRSA isolates, respectively. Respiratory tract specimens were mainly from elderly patients in respiratory medicine and geriatrics. The average age of the patients was over 80 . They were weak, with serious underlying diseases, low immunity, and hospitalized for longtime. They were not easy to recover during the treatment process and were prone to repeated infection. The amount and type of antibiotics used has been obviously increasing, causing multiple drug-resistance[20]. The specimens of orthopaedics and general surgery were mainly pus and wound secretion specimens. These infections could be caused by the hands of medical staff and surgical equipment.

Moreover, these patients were likely to suffer from multiple fractures and severe tissue injuries. MRSA infection was more likely to occur because of serious wound contamination and large surgical wounds[21].

Standard strains and 26 clinical isolates of MRSA strains were identified by automatic identification and drug susceptibility system (VITEK 2 compact microbiology analysis system, BioMérieux). According to the 2018 version of the Clinical and Laboratory Standards Institute (CLSI)[16], all strains were identified as MRSA. Drug susceptibility test showed that 26 MRSAs were all resistant to oxacillin, 5 to gentamicin, 17 to levofloxacin, 6 to amikacin, 22 to clindamycin, 19 to ciprofloxacin, 21 to erythromycin, 18 to moxifloxacin, 1 to compound neomycin, and 17 to tetracycline. All 26 strains were sensitive to rifampicin, linezolid and vancomycin(Table 2). In addition, these 26 MRSA isolates were identified by PCR, while the mecA gene was used to confirm the MRSA strain.

\section{The bacteriostatic effect of BBR, GEN, LEV and AMI on MRSA: BBR had strong bacteriostatic effect on MRSA}

BBR inhibited 26 strains of MRSA from different hospital sources. The MICs range of BBR was $32-256 \mu \mathrm{g} / \mathrm{mL}$; the $50 \% \mathrm{MIC}$ was $64 \mu \mathrm{g} / \mathrm{mL}$, and the $90 \% \mathrm{MIC}$ was $128 \mu \mathrm{g} / \mathrm{mL}$. $19.23 \%$ of the MRSA strains were resistant to GEN (strain: MRSA01 05), 5.38\% were resistant to LEV (strain: MRSA01 04, MRSA06 18), and 23.08\% were resistant to AMI (strain: MRSA02, MRSA04, MRSA07 10) (Table 3).

Bacteriostatic effect of BBR combined with antibiotics on MRSA: BBR combined with GEN and AMI significantly enhanced the bacteriostatic effect on MRSA, while BBR combined with LEV showed no significant change in the bacteriostatic effect on MRSA.

According to Table 2, among the 26 clinical isolates of MRSA strains, 5 were resistant to GEN, 17 were resistant to LEV and 6 were resistant to AMI. The bacteriostatic effect of BBR combined with these three antibiotics on MRSA was studied. After the combined action of BBR and GEN on 5 GEN-resistant MRSA strains, 4 strains displayed an additive effect, while 1 strain was indifferent. The FICls range was 0.53-1.06, 
and the median was 0.56 (additive effect). After the combined action of BBR and LEV on 17 LEV-resistant MRSA strains, only 3 displayed an additive effect, while the rest were indifferent; the FICls range was 0.62-1.5 and the median was 1.125 (indifferent effect). After the combined action of BBR and AMI on 6 AMI-resistant MRSA strains, 4 strains shown synergistic effect, 1 was additive, and 1 was indifferent. The FICls range was 0.16-1.25 and the median was 0.26 (synergistic effect) (Table 4).

BBR combined with antibiotics time-kill analysis: BBR combined with GEN and AMI significantly enhanced the bacteriostatic effect on MRSA, while BBR combined with LEV showed no significant change in the bacteriostatic effect on MRSA.

Of the 26 clinical MRSA strains, strain MRSA02, which was resistant to GEN, LEV, and AMl, was selected to assess the bacteriostatic effect of BBR combined with these 3 antibiotics. From the concentration-killing curve, the MICs of BBR, GEN, LEV, and AMI for MRSA were $128 \mu \mathrm{g} / \mathrm{mL}, 64 \mu \mathrm{g} / \mathrm{mL}, 128 \mu \mathrm{g} / \mathrm{mL}$, and $256 \mu \mathrm{g} / \mathrm{mL}$, respectively. As the concentration increased, the bacteriostatic effect became more distinct. No drug was added to the control group (Fig. 1A). BBR combined with GEN displayed a significant additive effect, and is positively correlated with the concentration. When 1/2 MIC BBR and 1/2 MIC GEN were used alone, there was no obvious bacteriostatic effect on MRSA02. When used in combination, the bacteriostatic effect was significantly enhanced (Fig. 1B). The bacteriostatic effect of BBR combined with LEV was additive. When 1/2 MIC BBR and 1/2 MIC LEV were used alone, there was no obvious bacteriostatic effect on MRSA02. When used in combination, the bacteriostatic effect was significantly enhanced (Fig. 1C). BBR combined with AMI showed an obvious synergistic bacteriostatic effect. When 1/2 MIC BBR and 1/2 MIC AMI were used alone, there was no obvious bacteriostatic effect on MRSA02. When used in combination, the bacteriostatic effect was obviously enhanced (better than that of BBR combined with GEN and LEV, respectively), achieving a bactericidal effect (Fig. 1D).

\section{Changes of conductivity of MRSA medium under BBR treatment: After BBR treatment, the conductivity of MRSA medium increased significantly}

MRSA02 strain, which was resistant to 3 antibiotics, was selected to observe the changes in conductivity of the culture medium after BBR treatment. The effect of BBR solution on the conductivity of MRSA02 medium is shown in Fig. 2. After treated with $512 \mu \mathrm{g} / \mathrm{mL}$ (8 MIC), $64 \mu \mathrm{g} / \mathrm{mL}(1 \mathrm{MIC})$ and $8 \mu \mathrm{g} / \mathrm{mL}$ (1/8 MIC) BBR for 4 hours, the conductivity increased by $8.14 \%, 13.08 \%$, and $12.01 \%$, respectively (Fig. $2 A$ ). When $512 \mu \mathrm{g} / \mathrm{mL}$ of BBR was applied to the MRSA02 for $0.5 \mathrm{~h}$, the conductivity of the culture medium was almost unchanged (Fig. 2B). After $64 \mu \mathrm{g} / \mathrm{mL}$ of BBR was applied to the MRSA02, the conductivity increased significantly and increased with time within a 3.5 hours period (Fig. 2C). After $8 \mu \mathrm{g} / \mathrm{mL}$ of BBR was applied to the MRSA02, the conductivity also increased significantly and increased with time within a 3.5 hours period (Fig. 2D).

Observation of changes in MRSA cell wall using TEM: high concentration of BBR induced the destruction and dissolution of MRSA cell wall structure and the leakage of bacterial contents, medium concentration of BBR made the bacteria swollen and thinned the cell wall of MRSA, while low concentration of BBR had no significant effect on MRSA structure 
Among the 26 clinical MRSA strains, the MRSA02 strain, which was resistant to 3 antibiotics, was selected to observe cell wall damage after BBR treatment. The cell wall of the MRSA02 strain was damaged to varying degrees after being cultured in low (8 $\mu \mathrm{g} / \mathrm{mL} ; 1 / 8 \mathrm{MIC})$, medium (64 $\mu \mathrm{g} / \mathrm{mL} ; 1 \mathrm{MIC})$ and high (512 $\mu \mathrm{g} / \mathrm{mL} ; 8$ MIC) BBR solutions (Fig. 3A-F). Low concentration $(8 \mu \mathrm{g} / \mathrm{mL})$ BBR did not result in any clear damage to the MRSA02 strain. This was evidenced by the MRSA02 strain having an intact structure and BBR crystals around the cell wall (Fig. 3A,3B). A medium concentration $(64 \mu \mathrm{g} / \mathrm{mL})$ of BBR thinned the cell wall of the MRSA02 strain, with BBR crystals adhering to the cell wall of the MRSA strain (Fig. 3C,3D). A high concentration (512 $\mu \mathrm{g} / \mathrm{mL}$ ) of BBR destroyed the cell wall structure of MRSA02 strain, and the contents of the MRSA02 strain leaked out, leading to bacterial lysis and death (Fig. 3E,3F).

\section{Analysis of RNA-seq results}

RNA sequencing was performed after USA300 was exposed to BBR at high concentration and low concentration for 3 hours. Sequencing results showed that there were 754 differentially expressed genes in the high concentration group compared with the normal control group, of which 561 genes were up-regulated and 193 genes were down-regulated. Compared with the control group, only 19 genes were differentially expressed in the low concentration group, of which 11 genes were up-regulated and 8 genes were down-regulated. Compared with the low concentration group, there were 590 differentially expressed genes in the high concentration group, of which 402 genes were up-regulated and 188 genes were down-regulated(Fig. 4A,4B,5A5C). Among them, ssaA and lytM genes were significantly up-regulated. The down-regulated genes were mainly serine protease family genes (Table 4). The expression of differentially expressed genes in standard strain USA300 was significantly increased by high concentration BBR, while the expression of differentially expressed genes in low concentration BBR group was not significantly changed.

\section{Discussion}

In recent years, the clinical application of traditional Chinese medicine and integrated Chinese and Western medicine has attracted attention. An increasing number of scholars have conducted related research, particularly in the investigation of the bacteriostatic effects of monomer components of traditional Chinese medicine. BBR can be used to treat traumatic infections in addition to its general bacteriostatic effect. For example, the Sanhuang lotion, a traditional Chinese medicine, is mainly composed of rhubarb, astragalus, and cork. Its main component is BBR, and it has been shown that Sanhuang lotion has a good therapeutic effect on ulcers infected with Staphylococcus aureus, effectively promoting healing of the ulcerated surface[22]. Our previous studies have shown that the traditional Chinese medicine Phellodendron amurense has a good bacteriostatic effect on Staphylococcus aureus in vitro, and the main inhibitory component of Phellodendron amurense is BBR[23]. Related studies confirmed that BBR has obvious bacteriostatic effect on MRSA, with a MIC range of $32-128 \mu \mathrm{g} / \mathrm{mL}[1,24]$. Similarly, our study found that BBR had an obvious bacteriostatic effect on 26 different MRSA strains in vitro, with a MIC range of $32-256 \mu \mathrm{g} / \mathrm{mL}$. The concentration-killing curve (Fig.1A) demonstrated that the bacteriostatic effect gradually enhanced as the concentration of BBR also increased. A BBR concentration of $128 \mu \mathrm{g} / \mathrm{mL}$ inhibited $90 \%$ of MRSA growth. 
Currently, antibiotic resistance is becoming more and more serious. The treatment of infections using single drug has reached a bottleneck. The combination of drugs will be a new choice for antimicrobial therapy[25]. Related studies have reported that BBR combined with antibiotics can reverse the resistance of bacteria to antibiotics. For example, the combination of BBR and gallnut has the effect of reversing multidrug-resistant Pseudomonas aeruginosa [26]. The traditional Chinese medicine Coptidis decoction for detoxification (BBR as main ingredient) combined with ampicillin, ceftazidime, cefmetazole, and ceftriaxone is capable of reversing drug-resistant E. coli [27]. In this study, BBR combined with the aminoglycoside antibiotics GEN and AMI displayed a bacteriostatic effect, where GEN had an additive effect $(0.5<\mathrm{FICl} \leq 1)$ on the 4 strains of MRSA. With the combination of $\mathrm{AMI}, 4$ strains of MRSA showed a synergistic effect $(\mathrm{FICl} \leq 0.5)$, while 1 strain displayed an additive effect $(0.5<\mathrm{FICl} \leq 1)$. $\mathrm{FICl}$ showed that BBR combined with $\mathrm{AMI}$ had a stronger bacteriostatic effect on MRSA than GEN. BBR combined with quinolone antibiotics had less of a bacteriostatic effect than BBR combined with aminoglycoside antibiotics, with only 3 strains displaying an additive effect $(0.5<\mathrm{FICl} \leq 1)$. The remaining 17 strains were indifferent $(1<\mathrm{FICl} \leq 2)$. The results of BBR combined with antibiotics showed that BBR combined with AMI had the best bacteriostatic effect on MRSA and almost had an effect of sterilization. AMI belongs to the aminoglycoside antibiotics and is mainly used for the treatment of Gram-negative bacilli infection. Its bacteriostatic mechanism is underpinned by the ability of the antibiotic to enter the bacteria through the cell wall of Gram-negative bacilli and irreversibly bind to the 30S ribosomal subunit. This results in inhibition of the synthesis of bacterial proteins thus achieving a bacteriostatic effect. MRSA are Gram-positive cocci, with thicker cell walls. We further explored the bacteriostatic mechanism of BBR by conductivity tests and TEM examination, to assess how BBR and AMI increased the bacteriostatic effect and the possible mechanism.

MRSA is a Gram-positive coccus, its cell wall is mainly composed of peptidoglycan and teichoic acid. Cell wall inhibitors such as $\beta$-lactam and vancomycin are beneficial to bacterial uptake of AMI[28,29]. Morphological changes in MRSA induced by BBR were observed by TEM. Low concentrations of BBR did not significantly damage the cell wall of MRSA. Combined with conductivity analysis, we speculate that it was possible for low concentrations of BBR to change the permeability of the cell wall of MRSA, resulting in increased release of small molecules from the bacteria while maintaining bacterial cell integrity (Fig. 3A,3B,2D). High concentrations of BBR rapidly and directly destroyed the structure of cell wall, resulting in the dissolution of the cell wall and bacterial death (Fig. 3E,3F). Therefore, after treatment with high concentration of BBR, the conductivity of MRSA culture medium changed significantly merely at the initial 0.5 hours, with little change thereafter, which further confirmed that BBR can inhibit the synthesis of MRSA cell wall. High concentration of BBR destroyed the structure of the MRSA cell wall, resulting in thinning or even lysis of the bacterial cell wall, enabling AMI to penetrate the cell wall more easily, with consequent action on the synthesis of DNA in bacteria. This resulted in further inhibition of synthesis of bacterial protein, leading to bacterial death. The results of this study confirmed that BBR combined with AMI can significantly enhance the bacteriostatic effect on MRSA.

In this study, we found that the expression of ssaA and lytM genes in the up-regulated genes of high concentration group was significantly different. According to the literature, these genes were all related to cell wall hydrolysis[30]. SsaA and lytM have potential WaIKR binding sites. WalKR system directly regulates the hydrolysis of bacterial cell wall[31]. It is speculated that high concentration of BBR increases the binding sites 
of ssaA and lytM to WalKR, and enhances the ability of WalKR system to hydrolyze bacterial cell wall, thus causing bacterial cell wall lysis and bacterial death. In the high concentration group, the expression of splB splF gene of serine protease family was significantly down-regulated. The serine protease family plays a hydrolytic role in protein metabolism, breaking the peptide bonds of macromolecules and forming smallmolecule propeptides[32], which are important component of bacterial cell wall [33]. Lack of small-molecule propeptides would affect the synthesis of bacterial cell wall, resulting in thinning and dissolution of bacterial cell wall. High concentration of BBR increased the expression of ssaA and lytM genes in USA300 and downregulated serine protease family genes, thus enhancing the damage of BBR to bacterial cell wall. However, the expression of ssaA, lytM and serine protease family genes in USA300 was not changed by low concentration of BBR. These results further validated the results of TEM and conductivity: high concentration of BBR induced cell wall lysis and change of cell wall permeability. The regulation mechanism of BBR on SsaA, lytM and serine protease genes will be further explored in our future study.

This study found that BBR had an excellent bacteriostatic effect on MRSA. The combination of BBR and aminoglycoside antibiotics significantly reduced the resistance of aminoglycoside antibiotics. In addition, BBR reversed bacterial resistance to antibiotics and enhanced antibiotic activity by inhibiting the synthesis of MRSA cell wall. We will study further on the bacteriostatic mechanism of BBR against bacteria.

\section{Declarations}

\section{Ethical approval and consent to participate}

This study was performed in accordance with the ethical standards detailed in the Declaration of Helsinki. The authors' institutional ethics committee has approved this study and all patients have provided written informed consent.

\section{Consent to publish}

Publication has been approved by all authors and the responsible authorities at the institution where the work is carried out. The authors confirm that the work described has not been published before and it is not under consideration for publication elsewhere.

\section{Availability of data and materials}

The datasets used or analysed during the current study are available from the corresponding author on reasonable request.

\section{Competing interests}

The authors report no conflicts of interest in this work.

\section{Funding}


No specific funding was obtained for the purpose of this study.

\section{Authors' contributions}

L.W conceived and designed the study. F.Z, W.G and S.J performed the experiments. F.Z and M.X analyzed the data and wrote the manuscript. L.W and P.L reviewed and edited the manuscript. All authors read and approved the manuscript.

\section{Acknowledgements}

We are grateful to the responsible authorities of Shanghai Eighth People's Hospital and Shanghai Pharmaceutical Institute for kindly supporting the progress of this study.

\section{References}

[1] Zuo G.Y.,Li Y., Han J., et al. Antibacterial and Synergy of Berberines with Antibacterial Agents against Clinical Multi-Drug Resistant Isolates of Methicillin-Resistant Staphylococcus aureus (MRSA)[J]. Molecules. 2012 Sep; 17(9): 10322-10330

[2]Arabestani M R, Rastiyani S, Alikhani M Y,et al. The Relationship Between Prevalence of Antibiotics Resistance and Virulence Factors Genes of MRSA and MSSA Strains Isolated from Clinical Samples, West Iran[J]. Oman Med J. 2018 Mar;33(2):134-140

[3]Li Y.Q., Huang W.H. Clinical analysis of nosocomial infection of methicillin-resistant Staphylococcus aureus [J].Chinese Journal of Hospital Infectiology, 2002,12(2):151-152.

[4] Qiu X.Q., Zheng L.Y., Chen X.J., et al. Literature Analysis in 41 Patients of Adverse Drug Reactions Caused by Vancomycin[J].Anti-infection Pharmcy $₫ 2017(4): 804-807$.

[5]McGuinness WA, Malachowa N, DeLeo FR.Vancomycin Resistance in Staphylococcus Aureus[J].Yale J Biol Med. 2017 Jun 23;90(2):269-281.

[6]Zhang Q., Piao X.S., Research progress on Bacteriostasis of berberine [J]. Chinese Journal of animal husbandry, 2010,46(3): 58-61.

[7]Musumeci R, Speciale A, Costanzo R, et al., Berberis aetnensis C. Presl. extracts: antimicrobial properties and interaction with ciprofloxacin[J]. Int J Antimicrob Agents. 2003 Jul;22(1):48-53.

[8]Han Y., Lee J. H., Berberine synergy with amphotericin B against disseminated candidiasis in mice[J]. Biol Pharm Bull. 2005 Mar;28(3):541-4.

[9] Chu M., Zhang M.B., Liu Y.C., et al. Role of Berberine in the Treatment of Methicillin-Resistant Staphylococcus aureus Infections[J]. Sci Rep. 2016,Apr, 22;6:24748 
[10]Lee D.U., Kang Y.J., Effects of 13-alkyl-substituted berberine alkaloids on the expression of COX-II, TNFalpha, iNOS, and IL-12 production in LPS-stimulated macrophages [J]. Life Sci. 2003, 73(11):1401-12.

[11]LI F.,Yi S.H.,Zhao C.Y.,et al.Studies on antivirus effect of Shuanghuanglian injection[J]. Chinese traditional and herbal Drug S, 2002, 1:52-55.

[12]Ruan H., Zhan Y.Y., Hou J., et al. Berberine binds RXRa to suppress $\beta$-catenin signaling in colon cancer cells[J]. Oncogene. $2017 ; 36(50): 6906-6918$.

[13]Kong W.J, Zhang H., Jiang J.D.,et al. Berberine reduces insulin resistance through protein kinase Cdependent up-regulation of insulin receptor expression[J]. Metabolism. 2009 Jan;58(1):109-119

[14]Kang Q.Z.,Ye F.,Yang S.Y., Efficacy of Berberine Intreating 17 Patients of Congestive Heart Failure[J].Chin J Nat Med, 2002, 4(2):83-84.

[15] Kong WJ, Xing XY, Xiao XH,et al. Effect of berberine on Escherichia coli, Bacillus subtilis, and their mixtures as determined by isothermal microcalorimetry[J]. Appl Microbiol Biotechnol. 2012 Oct;96(2):503-10.

[16]Performance Standards for Antimicrobial Susceptibility Testing:Sixteenth Information Supplement. Approved Guideline,Clinical and Laboratory Standards Institute consensus process[M]. Wayne, PA, USA, 2018.

[17]Fatma E.A., Tarek E.T., Mohamed E.A.,et al. A combination of silver nanoparticles and visible blue light enhances the antibacterial efficacy of ineffective antibiotics against methicillin-resistant Staphylococcus aureus (MRSA)[J].Ann Clin Microbiol Antimicrob ,2016; 15:48

[18]Atshan, S. S., Shamsudin, M. N., Lung, L. T., et al. Improved method for the isolation of RNA from bacteria refractory to disruption, including S. aureus producing biofilm[J]. Gene, 494(2):219-24

[19]Xu T, Han J, Zhang J., et al. Absence of Protoheme IX Farnesyltransferase CtaB Causes Virulence Attenuation but Enhances Pigment Production and Persister Survival in MRSA [J]. Front Microbiol. 2016; 7: 1625

[20]Wang J.,Zhao Y.L.,Yang A.Z. Experience in controlling multi-drug resistant bacterial infection in intensive care unit[J].Journal of Nurse Education, 2014,25(9): 860-861.

[21]Li Y.Y.. Nursing care of 36 open fracture patients with multiple drug-resistant bacteria infection[J].Medical theory and Practice $₫ 2013,26(12): 1648-1650$.

[22]Shen X.P., Xie B., Clinical observation of Sanhuang lotion wet compress in treating Staphylococcus aureus infection surface collapse [J].Academic Exchange of Orthopedics Professional Committee,2009.

[23]Zhao L.X.,Wang L., Primary investgation on in vitro bacteriostatic action of Amur-corktree to Staphylococcus aureus[J].Laboratory Medicine,September 2015,30(9):886-889

[24]Peng L.C., Kang S., Yin Z.Q.,et al.Antibacterial activity and mechanism of berberine against Streptococcus agalactiae[J].Int J Clin Exp Pathol 2015;8(5):5217-5223. 
[25]Luo J.Y.,Yan D.,Yang M.H.,et al. Multicomponent Therapeutics of Berberine Alkaloids[J].Evidence-Based Complementary and Alternative Medicine,2013:545898.

[26] Fang H., Wang R.Z., Zhang X.X. Study on Reversal of Antimicrobial Activity of Multidrug Resistant Pseudomonas aeruginosa by Combination of Chinese and Western Medicine [J]. 2017,7(29):389-391.

[27]Li Y.W.,Wang C.X., Bi Y.Y., Reversal Effect of Coptidis Decoction for Detoxification for drug resistance in Escherichia coli. Chinese Journal of Experimental Traditional Medical Formulae,2013,19(9):264-266.

[28]Davies JE.1983.Resistance to aminoglycosides:mechanisms and frequency.Rev Infect Dis 5(suppl 2):S261-S267.

[29] Wang H., Ma X.L., Qian Y., et al. Handbook of Clinical Microbiology [M]. 11th edition. Beijing: China Medical Electronic Audio-visual Press, 2017: 1518-1519

[30]Liu M. Antimicrobial activity and mechanism of emodin against methicillin-resistant Staphylococcus aureus in vivo and in vitro [D]. Chongqing, Third Military Medical University: 69-70.

[31]Sarah D, Ivo G B,,Tarek M,et al.New Insights into the WalK/WalR (YycG/YycF) Essential Signal Transduction Pathway Reveal a Major Role in Controlling Cell Wall Metabolism and Biofifilm Formation in Staphylococcus aureus. J Bacteriol. 2007 Nov;189(22):8257-69.

[32]Reed SB, Wesson CA, Bayles KW囚et al. Molecular Characterization of a Novel Staphylococcus aureus Serine Protease Operon. Infect Immun. 2001 Mar;69(3):1521-7.

[33]Katarzyna P, Michal Z, Grzegorz D.Staphylococcal SplB Serine Protease Utilizes a Novel Molecular Mechanism of Activation. J Biol Chem. 2014 May 30; 289(22): 15544-15553.

\section{Tables}

Table 1. Information of 26 strains of MRSA isolates 
department gender

Average VITEK 2 age

Compact

Num.of isolates positive for mecA

For MRSA

(strain)

\begin{tabular}{|c|c|c|c|c|c|}
\hline & male & female & & & \\
\hline Orthopaedics & 0 & 3 & 58.3 & 3 & 3 \\
\hline Respiration & 5 & 3 & 80.5 & 8 & 8 \\
\hline Geriatrics & 5 & 2 & 82.6 & 7 & 7 \\
\hline Surgery & 2 & 2 & 64.2 & 4 & 4 \\
\hline ICU & 0 & 3 & 84.7 & 3 & 3 \\
\hline Neurology & 0 & 1 & 87 & 1 & 1 \\
\hline Total & 12 & 14 & 76.7 & 26 & 26 \\
\hline
\end{tabular}

Table 2. Drug sensitivity analysis of 26 clinical isolates of MRSA strains 
ID OXA GEN LEV AMI CLI CIP ERY LZD MXF RFP SMZ TET VAN $\begin{array}{lllllllllllllll}\text { MRSA01 } & \mathrm{R} & \mathrm{R} & \mathrm{R} & \mathrm{S} & \mathrm{R} & \mathrm{R} & \mathrm{R} & \mathrm{S} & \mathrm{R} & \mathrm{S} & \mathrm{S} & \mathrm{R} & \mathrm{S}\end{array}$

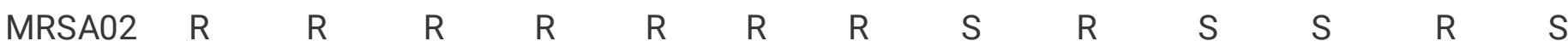
$\begin{array}{llllllllllllll}M R S A 03 & R & R & R & S & S & R & S & S & \text { I } & S & S & S & S\end{array}$ $\begin{array}{llllllllllllll}\text { MRSA04 } & \mathrm{R} & \mathrm{R} & \mathrm{R} & \mathrm{R} & \mathrm{R} & \mathrm{R} & \mathrm{R} & \mathrm{S} & \mathrm{R} & \mathrm{S} & \mathrm{S} & \mathrm{R} & \mathrm{S}\end{array}$ $\begin{array}{llllllllllllll}M R S A 05 & R & R & S & S & R & R & S & S & R & S & S & S & S\end{array}$ $\begin{array}{llllllllllllll}M R S A 06 & R & S & R & S & R & R & R & S & R & S & S & R & S\end{array}$ $\begin{array}{llllllllllllll}\text { MRSA07 } & R & S & R & R & R & R & R & S & R & S & S & R & S\end{array}$ $\begin{array}{lllllllllllllll}M R S A 08 & R & S & R & S & R & R & R & S & R & S & S & R & S\end{array}$ $\begin{array}{lllllllllllllll}M R S A 09 & R & S & R & S & R & R & R & S & R & S & S & R & S\end{array}$ $\begin{array}{llllllllllllll}M R S A 10 & R & S & R & R & R & R & R & S & R & S & S & S & S\end{array}$ $\begin{array}{llllllllllllll}\text { MRSA11 } & R & S & R & S & R & R & R & S & R & S & S & R & S\end{array}$ $\begin{array}{llllllllllllll}M R S A 12 & R & S & R & S & R & R & R & S & R & S & S & R & S\end{array}$

$\begin{array}{lllllllllllllll}M R S A 13 & R & S & R & S & R & R & R & S & R & S & S & R & S\end{array}$

$\begin{array}{lllllllllllllll}\text { MRSA14 } & R & S & R & S & R & R & R & S & R & S & R & R & S\end{array}$
$\begin{array}{llllllllllllll}M R S A 15 & R & S & R & S & R & R & R & S & R & S & S & R & S\end{array}$ $\begin{array}{llllllllllllll}\text { MRSA16 } & R & S & R & S & R & R & R & S & R & S & S & R & S\end{array}$ $\begin{array}{llllllllllllll}\text { MRSA17 } & \mathrm{R} & \mathrm{S} & \mathrm{R} & \mathrm{S} & \mathrm{R} & \mathrm{R} & \mathrm{R} & \mathrm{S} & \mathrm{R} & \mathrm{S} & \mathrm{S} & \mathrm{R} & \mathrm{S}\end{array}$

$\begin{array}{lllllllllllllll}\text { MRSA18 } & R & S & R & S & R & R & R & S & R & S & S & R & S\end{array}$

$\begin{array}{llllllllllllll}\text { MRSA19 } & \mathrm{R} & \mathrm{S} & \mathrm{S} & \mathrm{S} & \mathrm{S} & \mathrm{S} & \mathrm{S} & \mathrm{S} & \mathrm{S} & \mathrm{S} & \mathrm{S} & \mathrm{S} & \mathrm{S}\end{array}$
$\begin{array}{llllllllllllll}M & \text { MRA20 } & R & S & S & S & S & S & S & S & S & S & S & S\end{array}$ $\begin{array}{llllllllllllll}\text { MRSA21 } & R & S & S & S & S & S & S & S & S & S & S & R & S\end{array}$ $\begin{array}{llllllllllllll}M & \text { MRSA22 } & R & S & S & S & R & S & R & S & S & S & S & \text { I }\end{array}$ $\begin{array}{llllllllllllll}M R S A 23 & R & S & S & S & R & R & R & S & R & S & S & R & S\end{array}$ $\begin{array}{llllllllllllll}\text { MRSA24 } & R & S & S & S & R & S & R & S & S & S & S & S & S\end{array}$

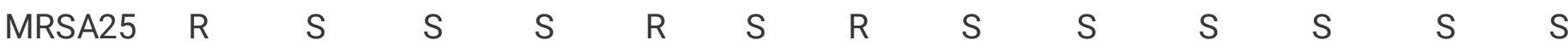
$\begin{array}{llllllllllllll}M R S A 26 & R & S & S & S & R & S & R & S & S & S & S & S & S\end{array}$ $\begin{array}{llllllllllllll}\text { Sum of } & 26 & 5 & 17 & 4 & 22 & 19 & 21 & 0 & 18 & 0 & 1 & 17 & 0\end{array}$ $\mathrm{R}$

Note区S: sensitive; R: resistant; I: intermediate; OXA: oxacillin; GEN: gentamicin; LEV: levofloxacin; AMI: amikacin; CLI: clindamycin; CIP: ciprofloxacin; ERY: erythromycin; LZD: linezolide; MXF: moxifloxacin; RFP: 
rifampicin; SMZ: sulfamethoxazole; TET: tetracycline; VAN: vancomycin

Table 3. Bacteriostatic effect of BBR and 3 antibiotics on MRSA

\begin{tabular}{|c|c|c|c|c|c|c|}
\hline Antimicrobials & $\begin{array}{l}\text { MIC of control } \\
\text { strains }(\mu \mathrm{g} / \mathrm{mL})\end{array}$ & $\begin{array}{l}\text { MIC of } 26 \text { clinical } \\
\text { isolates }(\mu \mathrm{g} / \mathrm{mL})\end{array}$ & & & & $\begin{array}{l}\text { aResistant/total } \\
\text { (\%Resistant) }\end{array}$ \\
\hline & ATCC29213 & Range & & $50 \%$ & $90 \%$ & \\
\hline & & aS & $\mathrm{aR}$ & & & \\
\hline BBR & 0.25 & $32-256$ & & 64 & 128 & $\mathrm{bN}$ \\
\hline GEN & 0.25 & $0.125-4$ & $\begin{array}{l}16- \\
64\end{array}$ & 0.5 & 32 & $5 / 26(84.6 \%)$ \\
\hline LEV & 0.0625 & $0.125-0.5$ & $\begin{array}{l}8- \\
256\end{array}$ & 16 & 256 & $17 / 26(34.6 \%)$ \\
\hline AMI & 2 & $0.125-2$ & $\begin{array}{l}64- \\
256\end{array}$ & 0.5 & 128 & $6 / 26 \rrbracket 76.9 \% \rrbracket$ \\
\hline
\end{tabular}

Note: a According to the 2017 version of CLSI: GEN: $\geq 16 \mu \mathrm{g} / \mathrm{mL}$ is Resistant; LEV: $\geq 4 \mu \mathrm{g} / \mathrm{mL}$ is Resistant; AMI: $\geq 64 \mu \mathrm{g} / \mathrm{mL}$ is Resistant; S: sensitive strains; R: Resistant strains. b N: not applicable.

Table 4. Bacteriostatic effect of BBR combined with antibiotics on MRSA

\begin{tabular}{|c|c|c|c|c|c|c|}
\hline $\begin{array}{l}\text { Antimicrobial } \\
\text { combination }\end{array}$ & $\begin{array}{l}\text { Range } \\
\text { of } \mathrm{FICl}\end{array}$ & $\begin{array}{l}\text { Median } \\
\text { of FICl }\end{array}$ & $\begin{array}{l}\text { Checkerboard } \\
\text { effect/strain }\end{array}$ & & & \\
\hline & & & synergistic & additive & indifferent & antagonistic \\
\hline BBR-GEN & $\begin{array}{l}0.53- \\
1.06\end{array}$ & 0.56 & 0 & 4 & 1 & 0 \\
\hline BBR-LEV & $0.62-1.5$ & 1.125 & 0 & 3 & 14 & 0 \\
\hline BBR-AMI & $\begin{array}{l}0.16- \\
1.25\end{array}$ & 0.26 & 4 & 1 & 1 & 0 \\
\hline
\end{tabular}

Note: $\mathrm{FICl} \leq 0.5,0.5<\mathrm{FICl} \leq 1,1<\mathrm{FICl} \leq 2,2 \leq \mathrm{FICl}$ represented synergistic, additive, indifferent and antagonistic effect, respectively.

Table 5. Effect of BBR on USA300 at different concentrations and analysis of differential genes 


\begin{tabular}{|c|c|c|c|c|c|c|}
\hline gene & $\begin{array}{l}\text { gene } \\
\text { symbol }\end{array}$ & $\begin{array}{l}\text { log2Fold } \\
\text { Change } \triangle B \text { vs } \\
A D\end{array}$ & $\begin{array}{l}\text { log2Fold } \\
\text { Change (B vs } \\
C \square\end{array}$ & $\begin{array}{l}\text { p-value } \\
\text { (B vs A) }\end{array}$ & $\begin{array}{l}\text { p-value } \\
\mathrm{QB} \text { vs } \\
\mathrm{C} \mathbb{}\end{array}$ & Description \\
\hline SAUSA300_2249 & ssaA & 3.42 & 3.45 & $\begin{array}{l}5.86 \mathrm{E}- \\
16\end{array}$ & $\begin{array}{l}9.62 \mathrm{E}- \\
15\end{array}$ & $\begin{array}{l}\text { secretory antigen } \\
\text { precursor ssaA }\end{array}$ \\
\hline SAUSA300_0270 & lytM & 1.66 & 1.45 & $\begin{array}{l}1.05 \mathrm{E}- \\
06\end{array}$ & $\begin{array}{l}8.34 \mathrm{E}- \\
06\end{array}$ & $\begin{array}{l}\text { peptidoglycan } \\
\text { hydrolase }\end{array}$ \\
\hline SAUSA300_1753 & splF & -2.73 & -3.16 & $\begin{array}{l}7.71 \mathrm{E}- \\
28\end{array}$ & $\begin{array}{l}4.34 \mathrm{E}- \\
39\end{array}$ & $\begin{array}{l}\text { serine protease } \\
\text { SplF }\end{array}$ \\
\hline SAUSA300_1754 & splE & -2.63 & -3.03 & $\begin{array}{l}1.75 \mathrm{E}- \\
25\end{array}$ & $\begin{array}{l}1.16 \mathrm{E}- \\
30\end{array}$ & $\begin{array}{l}\text { serine protease } \\
\text { SplE }\end{array}$ \\
\hline SAUSA300_1755 & splD & -3.16 & -3.62 & $\begin{array}{l}1.29 \mathrm{E}- \\
21\end{array}$ & $\begin{array}{l}9.67 \mathrm{E}- \\
21\end{array}$ & $\begin{array}{l}\text { serine protease } \\
\text { SplD }\end{array}$ \\
\hline SAUSA300_1756 & splC & -3.16 & -3.60 & $\begin{array}{l}2.11 \mathrm{E}- \\
34\end{array}$ & $\begin{array}{l}2.44 \mathrm{E}- \\
50\end{array}$ & $\begin{array}{l}\text { serine protease } \\
\text { SplC }\end{array}$ \\
\hline SAUSA300_1757 & splB & -2.93 & -3.01 & $\begin{array}{l}3.87 \mathrm{E}- \\
23\end{array}$ & $\begin{array}{l}4.03 \mathrm{E}- \\
21\end{array}$ & $\begin{array}{l}\text { serine protease } \\
\text { SplB }\end{array}$ \\
\hline
\end{tabular}

Note: A: Normal control group, B: High concentration group (1/2 MIC, $64 \mathrm{ug} / \mathrm{mL}) \otimes \mathrm{C}$ : Low concentration group $(1 / 8 \mathrm{MIC}, 16 \mathrm{ug} / \mathrm{mL})$.

Figures 
A

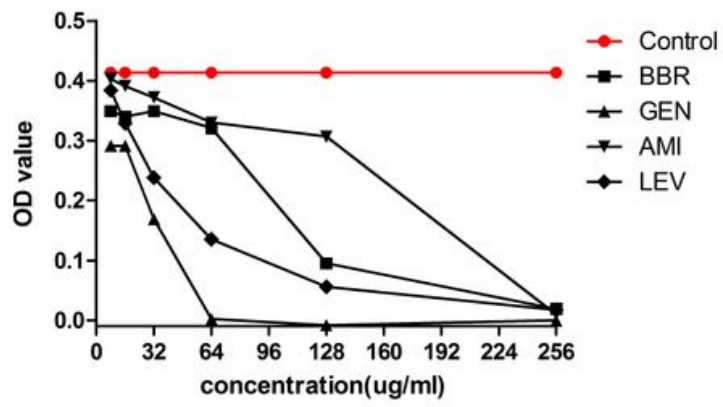

C

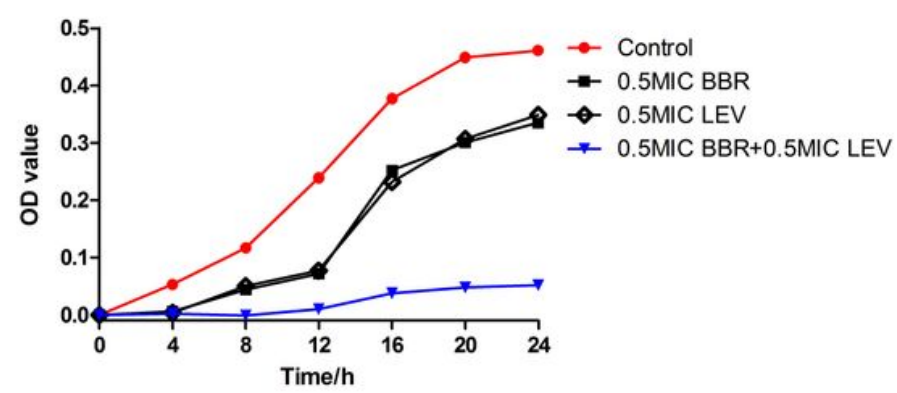

B

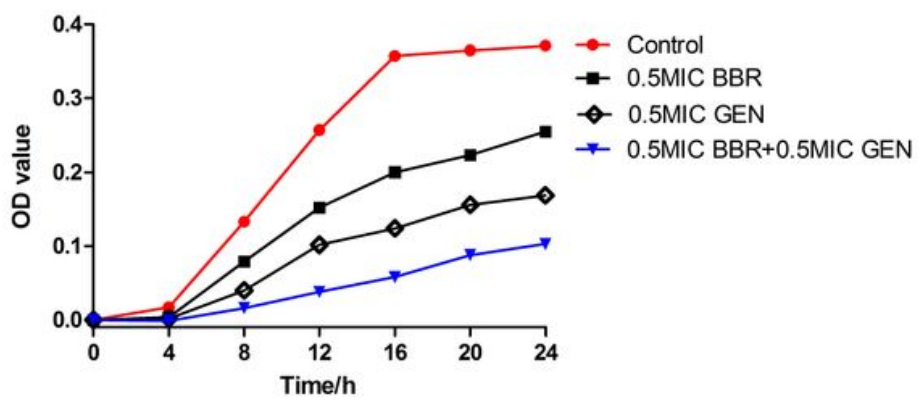

D

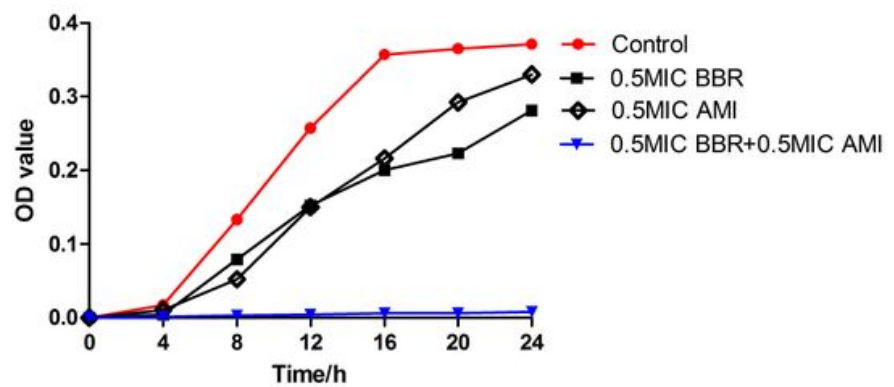

\section{Figure 1}

Time concentration-killing curve of BBR and antibiotics A: concentration- killing effect of BBR, GEN, LEV, and AMI on MRSA alone; B: bacteriostatic effect of BBR, GEN, and their combination on MRSA02 (MIC of BBR = 64 $\mu \mathrm{g} / \mathrm{mL}$, MIC of GEN $=32 \mu \mathrm{g} / \mathrm{mL}$ ). C: bacteriostatic effect of BBR, LEV, and their combination on MRSA02 (MIC of $\mathrm{BBR}=128 \mu \mathrm{g} / \mathrm{mL}$, MIC of LEV $=128 \mu \mathrm{g} / \mathrm{mL}$ ); D: bacteriostatic effect of BBR, AMl, and their combination on MRSA02 (MIC of BBR $=128 \mu \mathrm{g} / \mathrm{mL}$, MIC of AMI $=128 \mu \mathrm{g} / \mathrm{mL}$ ). 
A

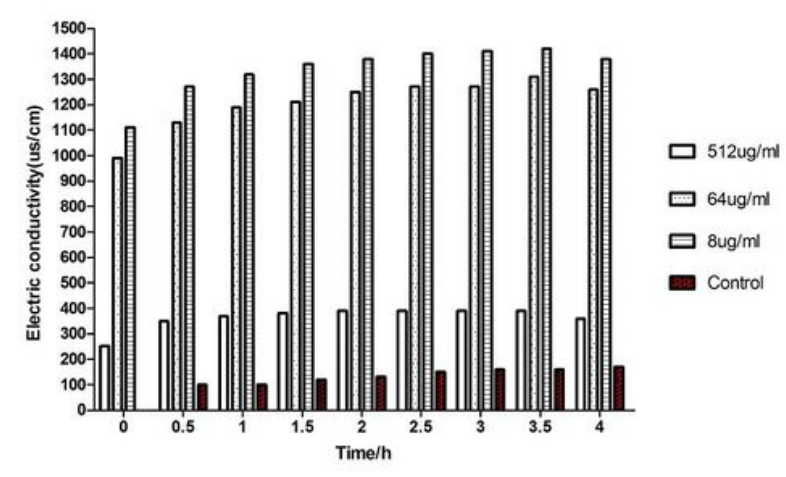

C

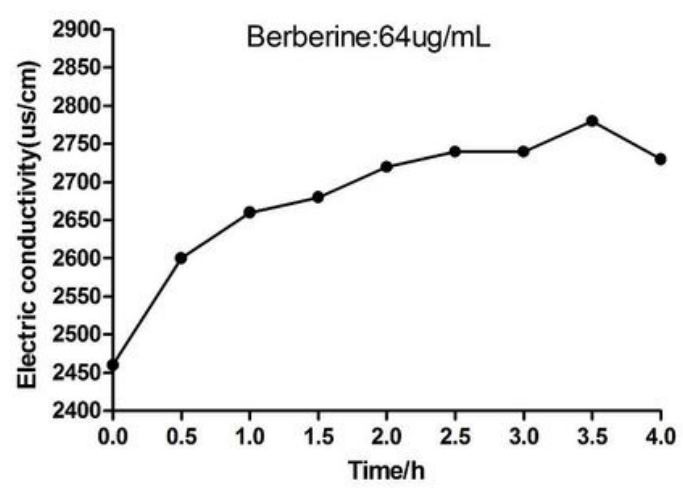

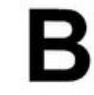
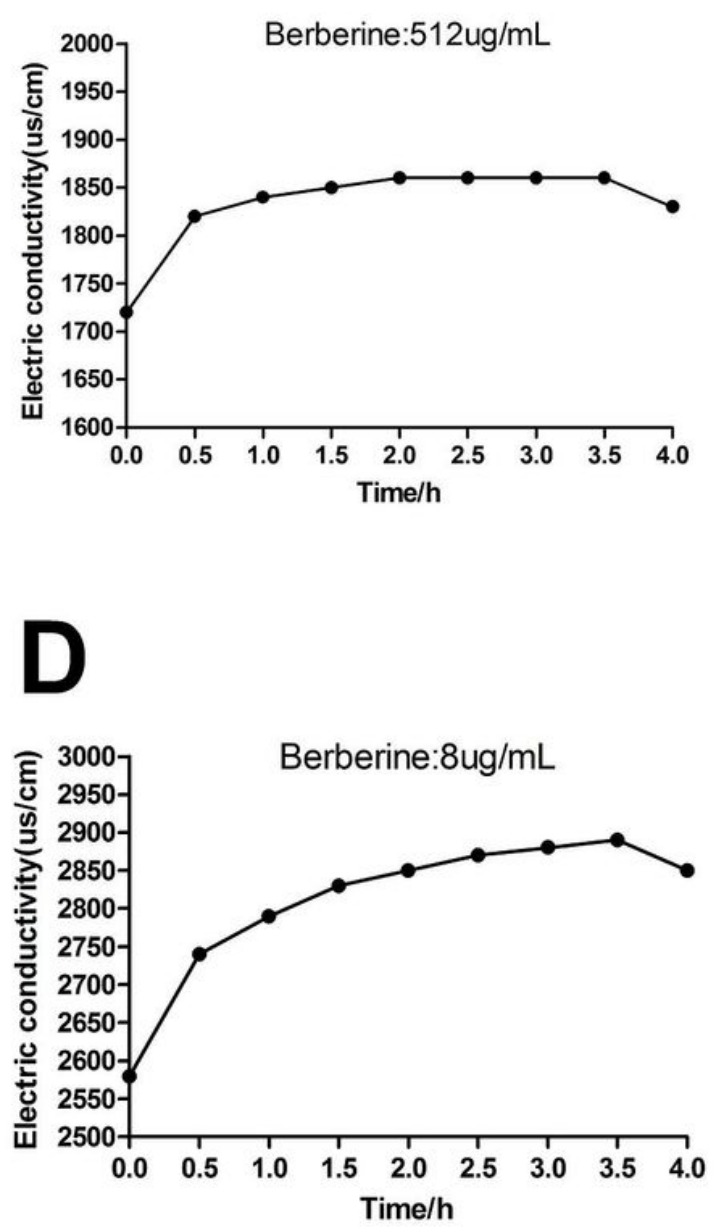

Figure 2

Effect of different concentrations of BBR solution on the conductivity of MRSA02 medium; A: The conductivity of the culture medium increased after the MRSA02 strain was treated with different concentrations of BBR solution; B: After treatment with $512 \mu \mathrm{g} / \mathrm{mL}$ BBR solution for $0.5 \mathrm{~h}$, the conductivity increased by $8.14 \%$, and then did not change significantly with time; C: After treatment with $64 \mu \mathrm{g} / \mathrm{mL}$ BBR for $4 \mathrm{~h}$, the conductivity increased by $13.08 \%$, increasing significantly with time; D: After treatment with $8 \mu \mathrm{g} / \mathrm{mL}$ BBR for 4 hours, the conductivity increased by $12.01 \%$, increasing significantly with time. 

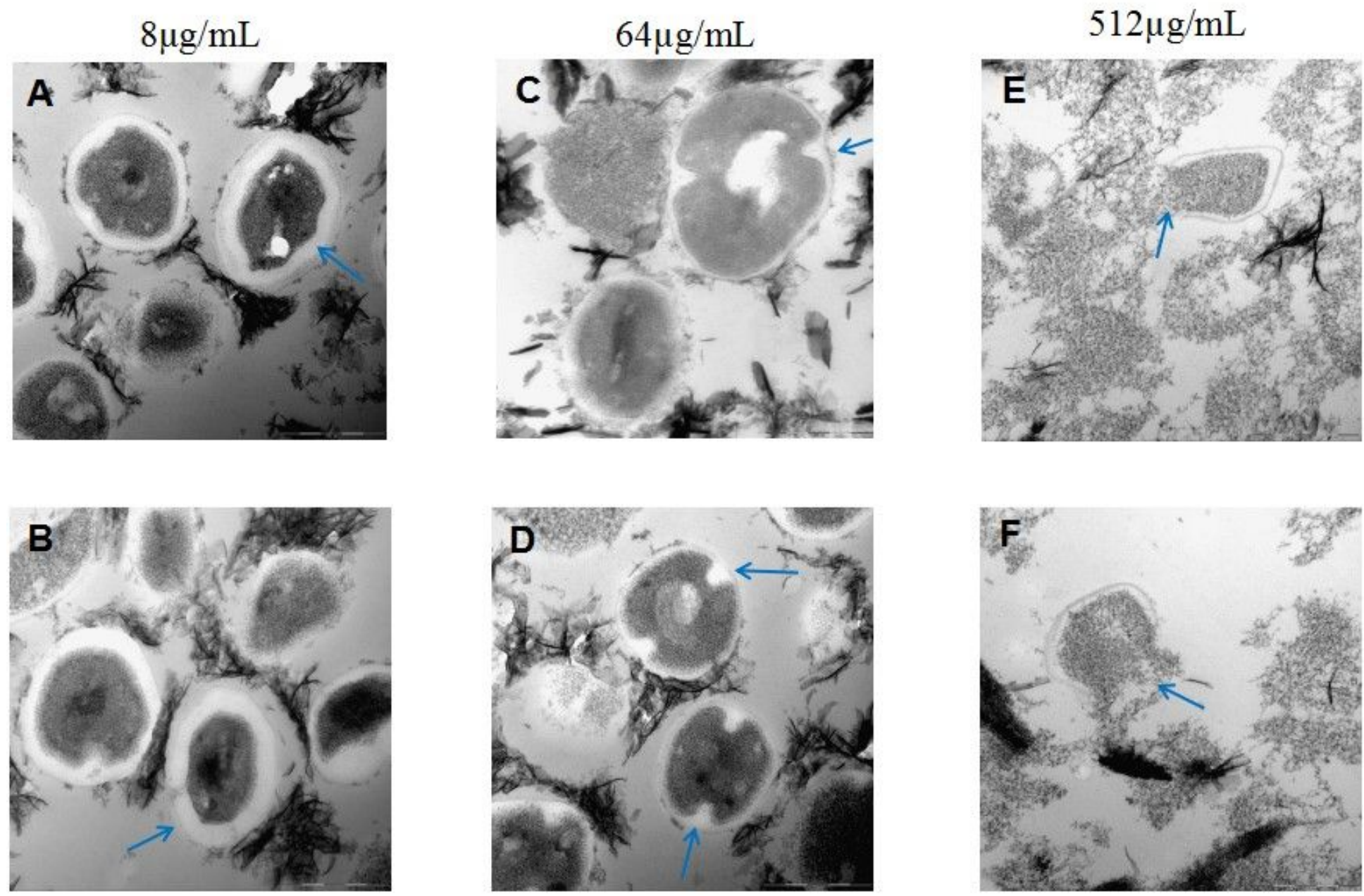

\section{Figure 3}

The cell wall of the MRSA02 strain x 80000 times visualized with TEM (Figure 3A-F). A-B: Low concentration (8 $\mu \mathrm{g} / \mathrm{mL})$ of BBR did not significantly damage the cell wall; C-D: medium concentration $(64 \mu \mathrm{g} / \mathrm{mL})$ of $B B R$ damaged the cell wall, resulting in cell wall thinning; E-F: High concentration $(512 \mu \mathrm{g} / \mathrm{mL})$ of BBR induced a large amount of cell wall structure destruction, cell lysis, significant leakage of intracellular contents, with consequent bacterial lysis, and a pronounced bactericidal effect. The black substance is BBR crystals. 

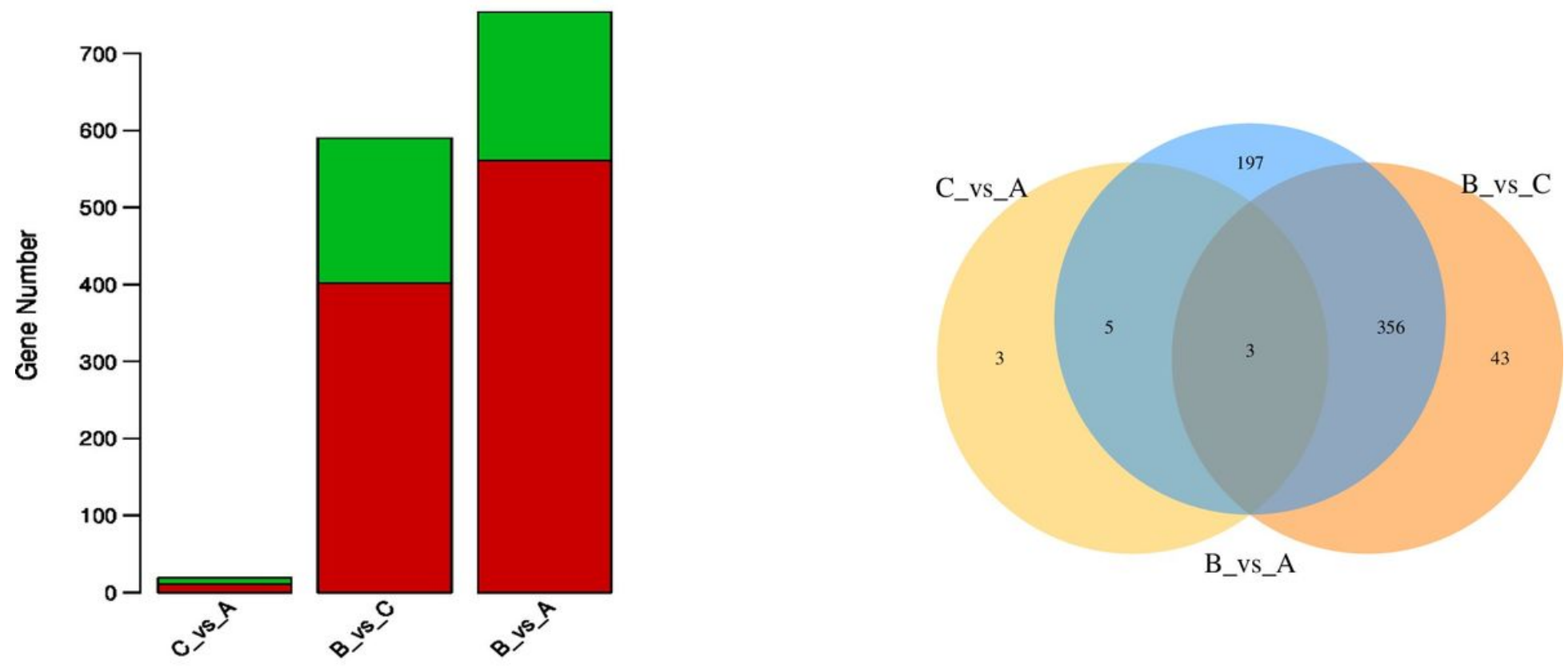

\section{Figure 4}

A: Statistical histogram of USA300 expression difference analysis. The horizontal axis is the group name, and the vertical axis is the number of up-down differential genes. Green represents down-regulated gene and red represents up-regulated gene. B: The Wayne Map of differential denes. Different groups are represented by different colors. Figures in the figure represent the number of differentially expressed genes that are specific or common. Overlapping region represents the number of differentially expressed genes shared by different groups, while non-overlapping region represents the number of differentially expressed genes unique to different comparison groups. A: Normal control group, B: High concentration group (1/2 MIC, $64 \mathrm{ug} / \mathrm{ml}) \llbracket \mathrm{C}$ : Low concentration group (1/8 MIC, $16 \mathrm{ug} / \mathrm{ml})$.
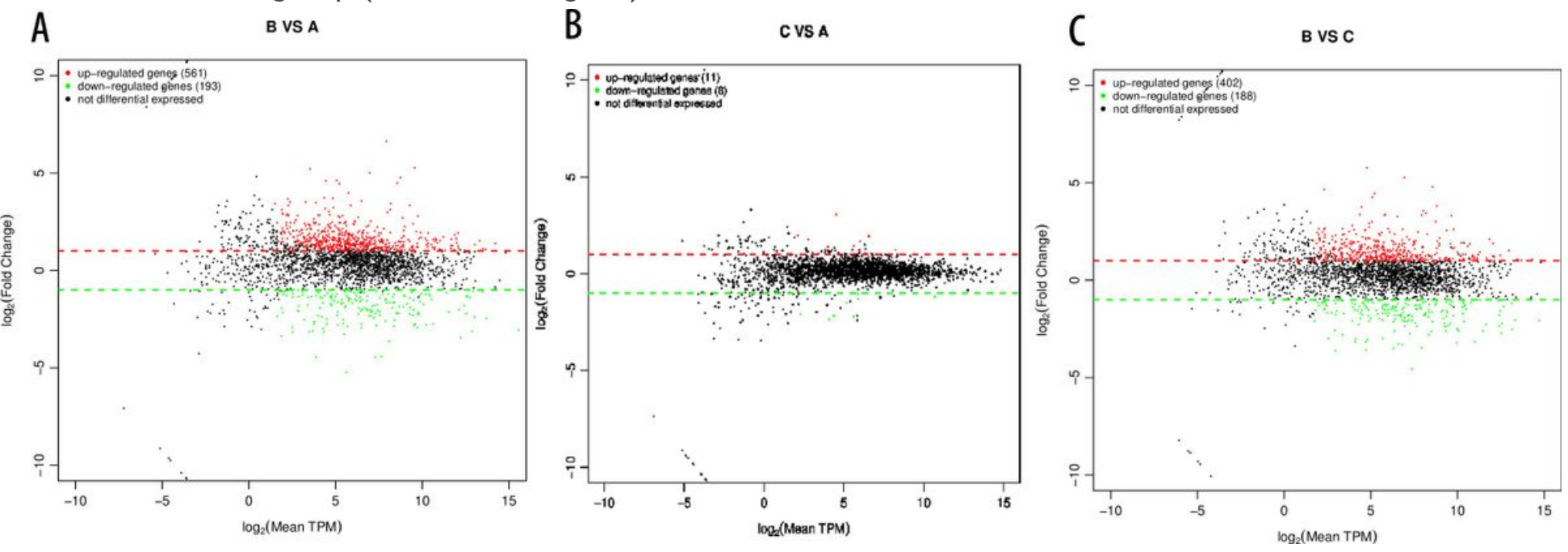

Figure 5 
A, B and $C$ groups expressed different MA maps. The horizontal axis is the log (TPM) mean of the two groups of samples, and the vertical axis is the log (Fold change) value. Each point in the graph represents a gene, where red represents an up-regulated gene, green represents a down-regulated gene, and black represents a non-differentiated gene. A: Normal control group, B: High concentration group (1/2 MIC, $64 \mathrm{ug} / \mathrm{ml}) \varangle \mathrm{C}$ : Low concentration group (1/8 MIC, $16 \mathrm{ug} / \mathrm{ml})$. 